\title{
Climate change and its impacts on river discharge in two climate regions in China
}

\author{
H. $\mathrm{Xu}^{1}$ and Y. Luo ${ }^{2}$ \\ ${ }^{1}$ National Climate Center, China Meteorological Administration, Beijing 100081, China \\ ${ }^{2}$ Ministry of Education Key Laboratory for Earth System Modeling, Center for Earth System Science, Tsinghua University, \\ Beijing, 100084, China \\ Correspondence to: H. Xu (xuhm@cma.gov.cn)
}

Received: 3 April 2015 - Published in Hydrol. Earth Syst. Sci. Discuss.: 30 July 2015

Accepted: 3 November 2015 - Published: 20 November 2015

\begin{abstract}
Understanding the heterogeneity of climate change and its impacts on annual and seasonal discharge and the difference between median flow and extreme flow in different climate regions is of utmost importance to successful water management. To quantify the spatial and temporal heterogeneity of climate change impacts on hydrological processes, this study simulated river discharge in the River Huangfuchuan in semi-arid northern China and in the River Xiangxi in humid southern China. The study assessed the uncertainty in projected discharge for three time periods (2020s, 2050s and 2080s) using seven equally weighted GCMs (global climate models) for the SRES (Special Reports on Emissions Scenarios) A1B scenario.

Climate projections that were applied to semi-distributed hydrological models (Soil Water Assessment Tools, SWAT) in both catchments showed trends toward warmer and wetter conditions, particularly for the River Huangfuchuan. Results based on seven GCMs' projections indicated changes from -1.1 to $8.6^{\circ} \mathrm{C}$ and 0.3 to $7.0^{\circ} \mathrm{C}$ in seasonal temperature and changes from -29 to $139 \%$ and -32 to $85 \%$ in seasonal precipitation in the rivers Huangfuchuan and Xiangxi, respectively. The largest increases in temperature and precipitation in both catchments were projected in the spring and winter seasons. The main projected hydrologic impact was a more pronounced increase in annual discharge in the River Huangfuchuan than in the River Xiangxi. Most of the GCMs projected increased discharge in all seasons, especially in spring, although the magnitude of these increases varied between GCMs. The peak flows were projected to appear earlier than usual in the River Huangfuchuan and later than usual in the River Xiangxi, while the GCMs were fairly consistent in
\end{abstract}

projecting increased extreme flows in both catchments with varying magnitude compared to median flows. For the River Huangfuchuan in the 2080s, median flow changed from -2 to $304 \%$, compared to a -1 to $145 \%$ change in high flow (Q05 exceedance threshold). For the River Xiangxi, low flow (Q95 exceedance threshold) changed from -1 to $77 \%$ and high flow changed from -1 to $62 \%$, while median flow changed from -4 to $23 \%$. The uncertainty analysis provided an improved understanding of future hydrologic behavior in the watershed. Furthermore, this study indicated that the uncertainty constrained by GCMs was critical and should always be considered in analysis of climate change impacts and adaptation.

\section{Introduction}

The impacts of climate and hydrological changes cover all spatial scales, from local to global (Lahmer et al., 2001; Coulthard et al., 2005). There is now substantial evidence indicating that over the most recent decades, the global hydrological cycle has already been responding to observed global warming (Bates et al., 2008), which includes an increasing atmospheric water vapor content and changing precipitation pattern. In many regions, the changing precipitation or melting of snow and ice is altering hydrological systems, affecting water resources in terms of quantity and quality (Jiménez Cisneros et al., 2014). To some extent, global climate change has also changed the availability of water resources in China. The precipitation, evaporation, and discharge of China's main rivers and lakes have changed to 
varying degrees. But, in general, the measured discharges of northern rivers such as the Haihe, Yellow, and Liaohe have decreased (Second National Assessment Report for Climate Change, 2011). In contrast, the water cycle in southern China is significantly different from that of northern China (Liu et al., 2004). Moreover, there is evidence that the water cycle will likely intensify further. So exploring the impacts of projected climate change on river discharge in southern and northern China will be an interesting topic.

Global climate models (GCMs) are useful tools for simulating climate systems and developing climate change research, which generate possible future climate scenarios. Within the IPCC AR5 (Intergovernmental Panel on Climate Change, Fifth Assessment Report) water sector, most hydrological projection studies use the precipitation and temperature downscaled from GCMs to driven hydrological models. From these studies, it is abundantly clear that climate change has the potential to substantially impact water resources. It highlights the uncertainties in projected changes to river runoff constrained by the uncertainties in regional climate projections. Generally, GCMs are considered to be the largest source of uncertainty for quantifying the impacts of climate change revealed by previous research (Rowell, 2006; Prudhomme and Davies, 2009; Wilby and Harris, 2006; Xu et al., 2011a; Kay et al., 2009). Considering the usefulness of climate scenarios for the decision-making and substantial uncertainties in climate projection, better quantification of the uncertainties is helpful to reduce the future risk and adopt adaptive water management.

In a previous study, two typical subcatchments, the River Huangfuchuan of the Yellow River and the River Xiangxi of the Yangtze River, were selected as study areas for quantitative evaluation of the projected impacts and multi-source uncertainties of climate change on river discharge for the 2050s (Xu et al., 2011a). The results indicated a consistent trend toward warmer and wetter conditions and increased river discharge in both catchments. Substantially larger increases in river discharge relative to the baseline were consistently projected for the semi-arid River Huangfuchuan catchment in northern China compared to the subtropical humid River Xiangxi catchment in southern China. In this paper, the study focused on the greatest source of uncertainty from GCMs individually and analyzed the changes in air temperature, precipitation, and river discharge of the two catchments in the early (2020s), middle (2050s), and late 21 st century (2080s). The climate projection used in this study was based on seven GCMs under the SRES (Special Reports on Emissions Scenarios) A1B emission scenario within the CMIP3 (Coupled Model Intercomparison Project phase 3) structure. SRES scenarios are based on assumptions about driving forces such as patterns of economic and population growth, technology development and other factors, and SRES A1B is widely used in climate change analysis and decision making in China. The study focused on extreme flow, constraining
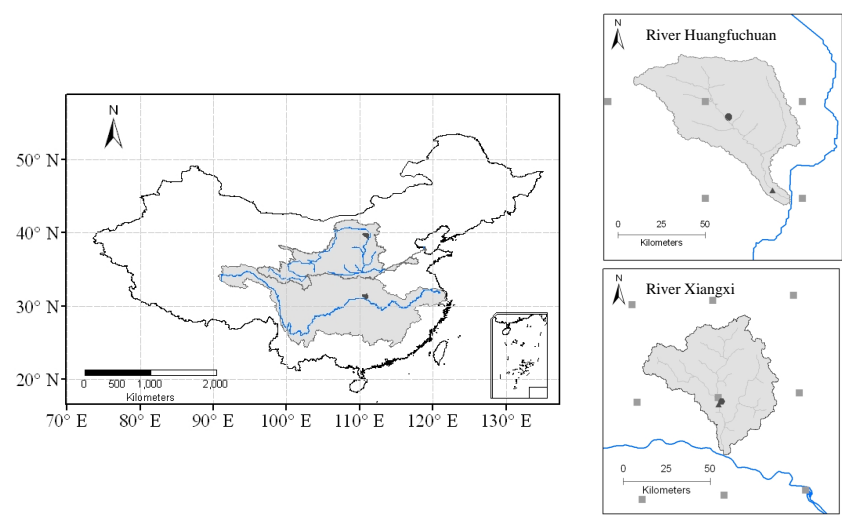

Figure 1. Location of selected subcatchments in the Yellow River and Yangtze River and climate stations (black circles), discharge stations (black triangles), and climate research unit (CRU) grid nodes (grey squares).

uncertainty in the projected river discharges, and examining the contrasts between the southern and northern catchments.

\section{Study areas and methodology}

\subsection{Characteristics of study areas}

The River Huangfuchuan is a primary catchment in the middle reaches of the Yellow River. The River Xiangxi is the first tributary supplying the Three Gorges Dam (Fig. 1). In addition to their being located in different climate regions, these two catchments also have different climate conditions and historical climate change trends (Xu et al., 2011a).

The River Huangfuchuan is located in northern China, has a semi-arid climate, and is primarily a pastoral farming region. The mean annual temperature is $7.5^{\circ} \mathrm{C}$, and increased at a rate of $0.24^{\circ} \mathrm{C}$ decade $^{-1}$ from 1961 to 2010 . The mean annual precipitation is $388 \mathrm{~mm}$, but it decreased over the period of 1961-2000 and increased over 2001-2010 at a rate of $0.87 \mathrm{~mm} \mathrm{decade}^{-1}$ (Gao et al., 2005; Sun et al., 2012). The mean annual runoff was $42.4 \mathrm{~mm}$ for 1956-2005, with a range of $74 \mathrm{~mm}$ in the $1950 \mathrm{~s}$ to $28 \mathrm{~mm}$ in the 1990s (Wang et al., 2009, 2012). Given the impacts of soil erosion, ecological water shortage, land desertification, flooding, and human water use, the River Huangfuchuan is very sensitive to global change (Yang et al., 2004).

The River Xiangxi lies in a subtropical humid climate region. Mean, minimum, and maximum annual air temperatures from 1961 to 2008 were $17.0,12.7$, and $22.9^{\circ} \mathrm{C}$, respectively. Minimum and maximum annual temperatures have increased over this period, especially since the 1980s. The mean annual precipitation during this period was $992 \mathrm{~mm}$ with a slight decrease in recent years. The mean annual runoff was $688 \mathrm{~mm}$ for 1961-2005, with a decrease from $733 \mathrm{~mm}$ in the 1960 s to $552 \mathrm{~mm}$ in the 1990s (Jin et al., 
1996). Due to land shortage, the natural vegetation has been progressively converted to farmland, exposing large areas of soil and leading to serious erosion and water loss (Jiang et al., 2002).

\subsection{Methodology}

\subsubsection{Hydrological model calibration and validation}

The hydrological model used in this study was the Soil Water Assessment Tool (SWAT) model developed by the United States Department of Agriculture (USDA). The model has been developed with the continuation of USDA Agricultural Research Service (ARS) modeling experiences for a period of over 30 years combined with the multiple user groups worldwide (Gassman et al., 2007). SWAT has been used worldwide at varying watershed scale and environmental conditions that represent a wide range of climates, soils, and land use (Arnold et al., 2012). A digital elevation model with a scale of $1: 250000$ was prepared by the China Fundamental Geographic Information Center. Spatial soil data with a scale of $1: 1000000$ were derived from the Environment and Ecology Scientific Data Center of western China, of the National Natural Science Foundation of China. Soil properties were generated from the Soil Attribute Data Set which is based on Soil Species of China (1993-1996) and other sources with, in total, information for 7300 soil profiles collected from all over China. The most recent land-use maps for the River Xiangxi compiled by the Hubei Land Management Bureau in the 1990s and land-use records from the Inner Mongolia Autonomous Region Department of Land and Resource in the 1980s were used to represent catchment land use. The monthly climate data set CRU TS3.0 (Mitchell and Jones, 2005), which covers the two catchments, was stochastically disaggregated to daily resolution following the procedures developed by Arnell (2003) and further described by Todd et al. (2011). Station-based daily precipitation and temperature within and around the two catchments obtained from the National Climate Information Center of the China Meteorological Administration were used for local calibration of the daily disaggregation procedure.

Based on the input digital maps, a total of 10 and 13 subwatersheds were generated based on dominant soil and land use for each subbasin. The SWAT model was calibrated for the monthly river discharge of the rivers Huangfuchuan and Xiangxi for a baseline period of 1961-1990, with the remaining 1991-1997 and 1991-1994 data of the rivers Huangfuchuan and Xiangxi for validation. Firstly, the hydrological model evaluation was based on the graphical techniques with hydrographs and percent exceedance probability curves for monthly timescales. The model performed well against the monthly river discharges observed from the Huangfu gauging station of the River Huangfuchuan and the Xingshan gauging station of the River Xiangxi, while peak flows of the River Xiangxi were very slightly underestimated. Then, the evaluation was performed with the statistics including coefficient of determination $\left(R^{2}\right)$ and Nash-Sutcliffe efficiency (Ens). Model performance was evaluated as "satisfactory" if Ens $>0.50$ and $R^{2}>0.58$ (Moriasi et al., 2007); the performance statics Ens and $R^{2}$ are "satisfactory", except for the River Xiangxi in the calibration period with 0.43 and 0.44 , respectively. More details on input data sets, model calibration and validation results can be found in Xu et al. (2011a).

\subsubsection{Climate scenarios and hydrological projection}

The climate change projection data used in this study utilized seven GCMs from the CMIP3 data set under the SRES A1B emission scenario from 2010 to 2099, which included the following: UKMO HadCM3, UKMO HadGEM1, NCAR CCSM3.0, MPI ECHAM5, IPSL CM4, CSIRO MK3.0, and CCCma CGCM3.1. The period from 1961 to 1990 was used as the baseline, based on CRU TS3.0 gridded $\left(0.5^{\circ} \times 0.5^{\circ}\right)$ climate data. This study utilized the monthly temperature and precipitation projections from different GCMs using the ClimGen pattern-scaling technique (Osborn, 2009), which were subsequently downscaled to daily resolution. ClimGen created monthly climate scenarios through a pattern-scaling approach in which climate change patterns were simulated by a suite of GCMs (Osborn, 2009) and later downscaled to daily resolution following the procedure outlined above. The baseline period 1961-1990 was used to represent the "present day" climatology of the study area. Climate scenarios were centered around three time periods: 2020s (20102039), 2050s (2040-2069), and 2080s (2070-2099), representing the early, middle, and late of 21 st century. The annual and seasonal changes for projected temperature and precipitation were compared with the baseline period for two catchments over the three time horizons.

For subsequent hydrological projections, this study adopted downscaled projection data derived from the GCMs and validated SWAT models and projected the impact of climate change on river discharges from 2010 to 2099. The average hydrograph, and changes of annual and seasonal discharge were calculated using 30 years of projected monthly discharge data over each of the three time horizons and then compared with the simulated discharge based on CRU_TS3.0 climate data for the baseline period rather than the actual observed discharge data. This technique was used to avoid systematic errors that the SWAT model would introduce in comparing the projection period with the baseline period.

The uncertainty envelope of the climate projections was shown as a function of each GCM, with the assumption that each climate projection had an equal probability of occurrence. Using the result from 30-year simulations, empirical probability density functions (PDFs) of the projected annual temperature, annual precipitation, and simulated annual discharge were generated. The PDFs indicated the range of possible values for each variable and for each time horizon. 

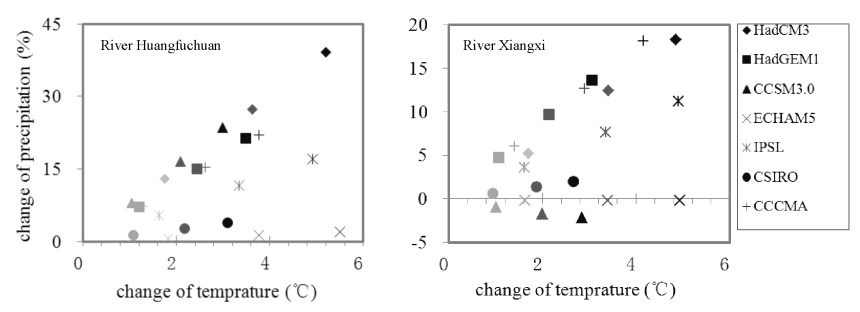

Figure 2. Scatter plots of annual temperature and precipitation changes for seven GCM projections for the 2020s, 2050s and 2080s time horizons for the rivers Huangfuchuan and Xiangxi (compared to the 1961-1990 baseline; 2020s: light grey; 2050s: dark grey; 2080s: black).

\section{Results}

\subsection{Projected climate change}

\subsubsection{Changes of annual temperature and precipitation}

The mean annual temperature and precipitation projections from the seven GCMs for the rivers Huangfuchuan and Xiangxi are shown in Fig. 2. All seven GCM projections for the River Huangfuchuan indicated warming and wetting, with air temperature rising from 1.0 to $1.8^{\circ} \mathrm{C}, 2.1$ to $3.8^{\circ} \mathrm{C}$ and 3.0 to $5.5^{\circ} \mathrm{C}$ in the $2020 \mathrm{~s}, 2050 \mathrm{~s}$ and $2080 \mathrm{~s}$, respectively, while precipitation increased from 1 to $13 \%, 1$ to $27 \%$ and 2 to $39 \%$, respectively, for the same periods. For the River Xiangxi, the GCM projections consistently showed rising temperatures, with temperature rising from 0.9 to $1.7^{\circ} \mathrm{C}, 1.9$ to $3.4^{\circ} \mathrm{C}$ and 2.7 to $4.9^{\circ} \mathrm{C}$ in the $2020 \mathrm{~s}, 2050 \mathrm{~s}$ and $2080 \mathrm{~s}$, but two GCMs projected precipitation decreases (CCSM3.0 and ECHAM5), while precipitation changed from -1 to $6 \%,-2$ to $13 \%$ and -2 to $18 \%$, respectively, for the same periods.

The projected ratio of precipitation changing with temperature ranged from about $7.8 \%{ }^{\circ} \mathrm{C}^{-1}$ (CCSM3.0) to $0.3 \%{ }^{\circ} \mathrm{C}^{-1}$ (ECHAM5) for the River Huangfuchuan, with four GCMs that projected a ratio greater than $5.8 \%{ }^{\circ} \mathrm{C}^{-1}$ and three $\mathrm{GCM}$ projections of less than $3.4 \%{ }^{\circ} \mathrm{C}^{-1}$. There were three GCMs that projected a ratio greater than $3.5 \%{ }^{\circ} \mathrm{C}^{-1}$ and four GCM projections of less than $2.3 \%{ }^{\circ} \mathrm{C}^{-1}$ with two GCM projections that showed the precipitation decrease with warming, as mentioned before for the River Xiangxi.

\subsubsection{Changes of seasonal temperature and precipitation}

The projected seasonal temperature and precipitation (Fig. 3) indicated that it was consistently warmer in winter, spring, and summer in the River Huangfuchuan, with temperature increases ranging from 0.7 to $5.3^{\circ} \mathrm{C}$ in the $2020 \mathrm{~s}$ and from 2.5 to $8.6^{\circ} \mathrm{C}$ in the $2080 \mathrm{~s}$. Winter showed the greatest temperature rise, while several GCMs projected temperature decreases in autumn. For the River Xiangxi, all seven GCMs projected temperature increases in all seasons, ranging from
0.3 to $2.1^{\circ} \mathrm{C}$ in the 2020 s and 1.9 to $7.0^{\circ} \mathrm{C}$ in the $2080 \mathrm{~s}$. The temperature increases appeared to be greatest in autumn and least in spring. Both the estimated emissions of greenhouse gases and the total radiative forcing increases are greater at the end of 21 st century than earlier in the 21 st century, which caused the projected temperatures to be larger in the 2080 s compared to the 2020s. The projected seasonal changes are generally consistent with the projected seasonal changes in eastern Asia. The projected temperature increases are generally greater in winter and autumn compared to summer and spring in eastern Asia; this is supported by regional averages of temperature projections from a set of 21 global models for the A1B scenario by CMIP3 (Christensen, 2007), and CMIP5 results support this assessment (Christensen, 2013).

There were consistent increases in projected precipitation for winter and spring across the seven GCMs, but the consistency was poorer for summer and autumn precipitation changes. The ratio of percentile precipitation changes with temperature was the highest in winter and the lowest in summer in both catchments. The projected seasonal precipitation increased more for the River Huangfuchuan than for the River Xiangxi. For the River Xiangxi, seasonal mean precipitation increases in the 2020s and 2080s were 1.3 and $8.6 \%$, respectively, while the seasonal mean precipitation increases were 8.6 and $33.6 \%$ for the River Huangfuchuan during the same periods. The difference in projected precipitation among the GCMs increased over time horizons in each season, with the maximum range in winter and minimum range in summer.

\subsubsection{Uncertainties in temperature and precipitation projections}

Based on the climate change projections, the calculated PDFs showed the possible ranges of temperature and precipitation changes during the three time horizons (Fig. 4). The most important findings were the increased uncertainties in projected mean annual temperature and precipitation toward the end of the 21 st century. Furthermore, the projected mean annual temperature increased in all of the GCMs, while precipitation projections showed relatively consistent increases and shifts toward extreme conditions, with the exception of ECHAM5 and CCSM3.0 (Community Climate System Model) which showed a decrease in the River Xiangxi. However, while the GCMs showed a consistent direction of changes in temperature and precipitation, there were large differences in the magnitudes of increase. Finally, the magnitudes of the temperature and precipitation changes in the River Huangfuchuan were more than in the River Xiangxi, indicating that the climate change uncertainty was greater for the River Huangfuchuan.

For projected temperature, the increase from CCSM3.0 and CSIRO (Commonwealth Scientific and Industrial Research Organisation) showed the smallest magnitude of about 1.0 and $3.0^{\circ}$ for the River Huangfuchuan and 0.9 and $2.8^{\circ}$ for 

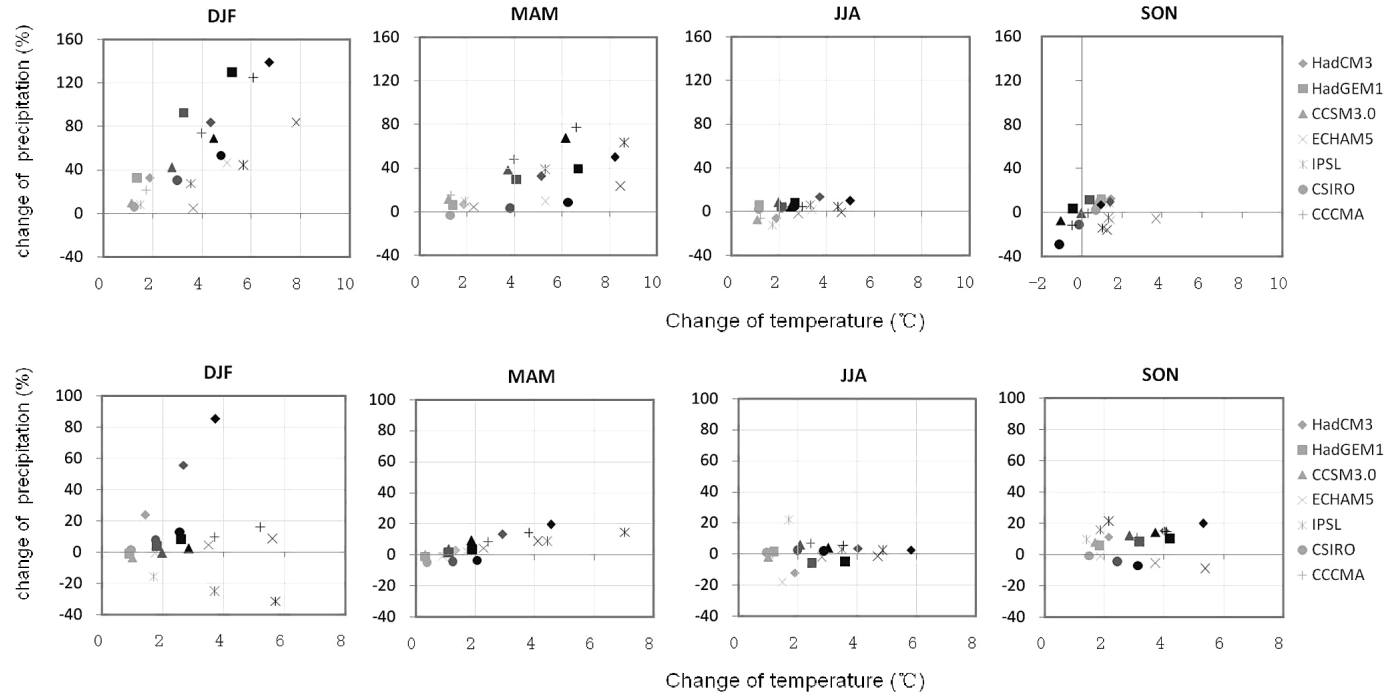

Figure 3. Scatter plots of seasonal temperature and precipitation changes for seven GCM projections for the 2020s, 2050s and 2080s time horizons for the rivers Huangfuchuan (top) and Xiangxi (bottom) (compared to the 1961-1990 baseline; 2020s: light grey; 2050s: dark grey; 2080s: black).
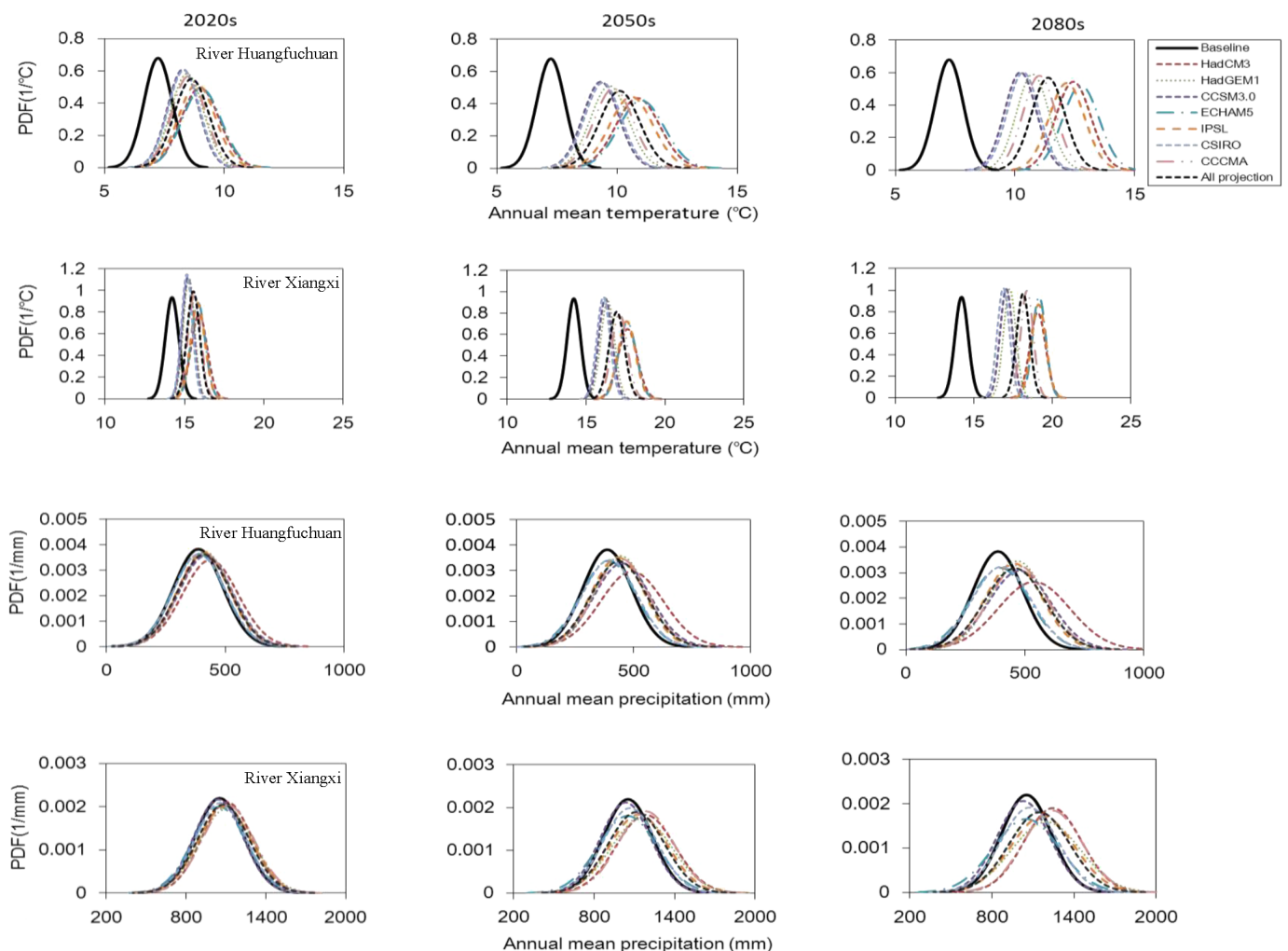

Figure 4. Probability density functions of annual mean temperature and annual precipitation for seven GCM projections for the 2020s, 2050s and 2080s time horizons and for the 1961-1990 baseline for the rivers Huangfuchuan and Xiangxi.

the River Xiangxi for the 2020s and 2080s, respectively. The projected warming from ECHAM5 and HadCM3 (Hadley Centre Coupled Model, version 3) were at the other end of the spectrum for the River Huangfuchuan with an increase of 1.8 and $5.3^{\circ}$ for the same horizons, and the HadCM3, 
ECHAM5 and IPSL (Institut Pierre Simon Laplace) models had an increase of 1.7 and $4.9^{\circ}$.

For the River Huangfuchuan, the projected precipitation from ECHAM5 and CSIRO showed the smallest increase of less than 5.0 and $15.0 \mathrm{~mm}$ for the $2020 \mathrm{~s}$ and $2080 \mathrm{~s}$, while the HadCM3 showed the largest increase of about 50 and $150 \mathrm{~mm}$ for the 2020s and 2080s. For the River Xiangxi, the projected precipitation from ECHAM5 and CCSM3.0 showed a maximum decrease of about 10 and $20 \mathrm{~mm}$ for the 2020s and 2080s, while the CCCma (Canadian Centre for Climate Modelling and Analysis) and HadCM3 models showed the largest increase of about 60 and $190 \mathrm{~mm}$ for the 2020s and 2080s. The projected precipitation from CCSM3.0 and ECHAM5 showed a decrease for the River Xiangxi and an increase for the River Huangfuchuan for the three horizons. Among all GCMs, only HadCM3 showed substantial increase for projected precipitation for both catchments.

PDFs also showed that the mean annual temperature of the River Huangfuchuan in the 2080s was outside the natural temperature variation of the baseline, with the cold years in the 2080s warmer than the warmest years of the baseline. For the River Xiangxi, a similar pattern was simulated in the 2050s. The projected precipitation from all seven GCMs indicated that the rivers Huangfuchuan and Xiangxi will become wetter in the future and the frequency of extreme wet and dry years will also increase compared with the baseline.

\subsection{Projected discharge based on hydrological model}

\subsubsection{Changes of average hydrograph}

The projected average hydrographs of the rivers Huangfuchuan and Xiangxi over each of the three time horizons are presented in Fig. 5. The average hydrograph shows a general increase in discharge for the rivers Huangfuchuan and Xiangxi, with the exception of HadGEM1 and ECHAM5 which project a decrease in the River Xiangxi in summer (JuneAugust). The projected peak discharge showed a great increase and appeared earlier during the flood season in the River Huangfuchuan, while that of the River Xiangxi appeared later.

\subsubsection{Changes of annual and seasonal river discharge}

The changes in projected annual and seasonal river discharges are presented in Fig. 6. The projected annual river discharge decreased for the River Xiangxi in ECHAM5 with the magnitude ranging from -1 to $-1.7 \%$ during the three time horizons, and the projections from other GCMs showed an increase with the magnitude ranging from 0.3 to $7 \%$ in the 2020 s, 2 to $18 \%$ in the 2050s, and 3 to $25 \%$ in the 2080s. The projected annual river discharges in the River Huangfuchuan showed a consistent increase across all of the GCMs with the magnitude ranging from 5 to $29 \%$ in the 2020 s, 12 to $73 \%$ in the 2050s, and 17 to $142 \%$ in the 2080s. The comparison between the two catchments showed that the River Huangfuchuan had a substantially greater increase in annual river discharge than the River Xiangxi.

The changes in projected seasonal river discharge indicated the larger differences for both the magnitude and direction compared to the changes in projected annual river discharge across the GCMs for the three time horizons, especially in the River Xiangxi. The changes in projected discharge increased the most in spring for the River Huangfuchuan.

\subsubsection{Changes of extreme discharge}

Figure 7 shows the projected extreme discharges for both catchments. There was general increase in the extreme discharges (Q05 for high flow and Q95 for low flow) for both catchments in the three time horizons, and the increase for the River Huangfuchuan was more substantial than for the River Xiangxi. However, the changes in extreme discharge were totally different compared to the median flow (Q50). The increase in projected high flow for the River Huangfuchuan was less than the increase in median flow, with substantial uncertainty in the projected median flow. However, the River Xiangxi showed an increase in projected extreme discharge that was more substantial than that of median flow, with a larger range.

For the River Huangfuchuan, CSIRO was the only model that projected decreases of Q05 and Q50 in the 2020s; the projected Q05 under all of the other GCMs increased over the three time horizons. The projected maximum changes in Q05 and Q50 in the River Huangfuchuan during the 2020s were $39 \%$ from CGCM3.1 and $38 \%$ from IPSL, while the projected maximum changes in Q05 were 70 and $146 \%$ from HadCM3 in the 2050s and 2080s, and the projected maximum changes in Q50 were 119 and $304 \%$ from HadCM3 in the 2050s and 2080s.

For the River Xiangxi, HadGEM1, ECHAM5, and CSIRO projected a slight decrease in Q50, whereas most GCMs projected an increase in extreme discharge over the three time horizons. The projected Q05 from HadGEM1 decreased during the 2050s and 2080s while it increased for the other GCMs. The maximum increase for Q05 was from the CCSM3.0, with the magnitudes of $17 \%$ (2020s), $41 \%$ (2050s), and 63\% (2080s). The projected Q95 decreased in ECHAM5 and IPSL during the 2080s while it increased for other GCMs, and the maximum increases were from the HadCM3 with the magnitudes of $27 \%$ (2020s), $38 \%$ (2050s), and $77 \%$ (2080s). The consistent and large increases in Q05 from CCSM3.0 and Q95 from HadCM3 for the three time horizons should be considered when using this information for decision making. 

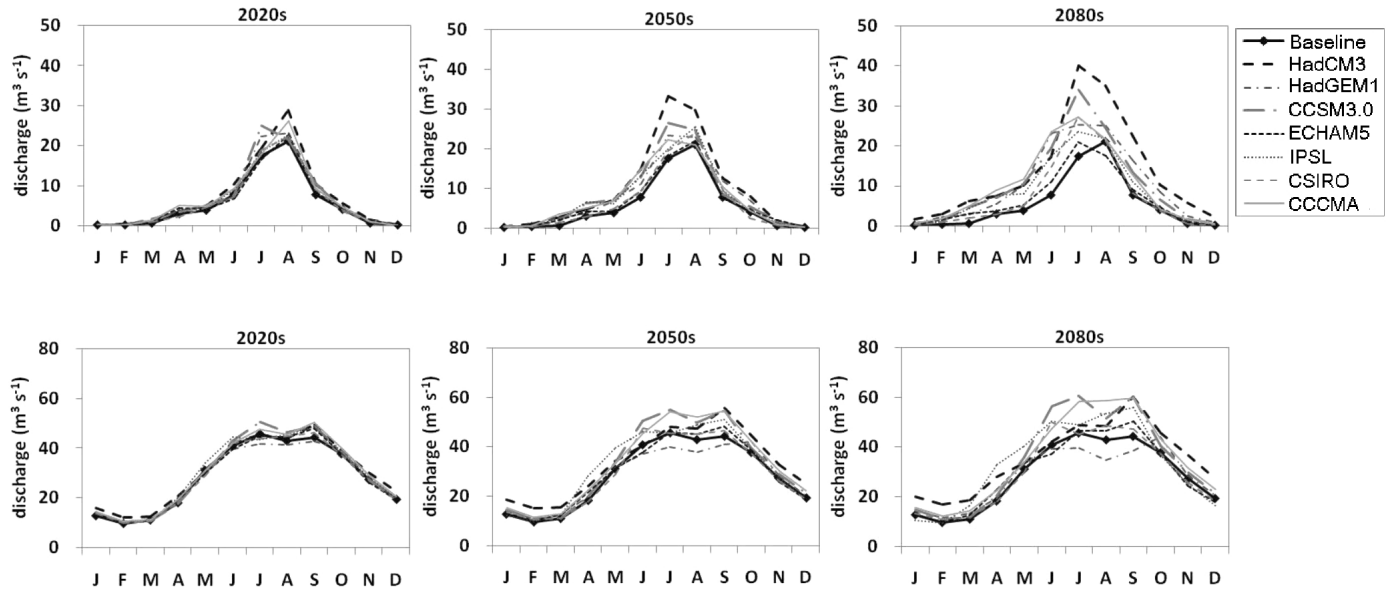

Figure 5. Average hydrographs for seven GCM projections for the 2020s, 2050s and 2080s time horizons and the 1961-1990 baseline for the rivers Huangfuchuan (top) and Xiangxi (bottom).
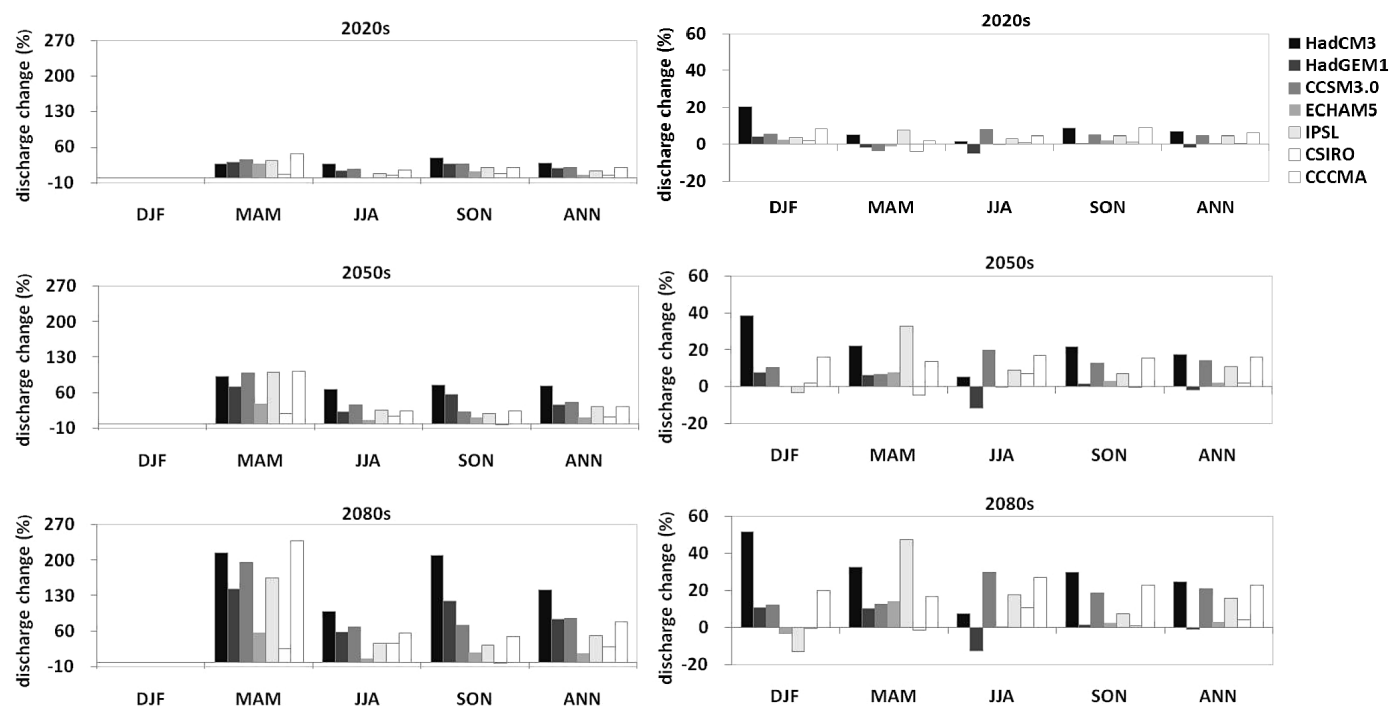

Figure 6. Seasonal and annual discharge changes for seven GCM projections for the 2020s, 2050s and 2080s time horizons for the rivers Huangfuchuan (left) and Xiangxi (right) (compared to the 1961-1990 baseline).

\subsubsection{Uncertainty in river discharge projections}

The PDFs of the mean annual river discharges are shown in Fig. 8. There were large uncertainties in the model projections, especially toward the end of the 21 st century. Some models behaved very differently than others, as shown by the results of HadCM3 for the River Huangfuchuan and HadGEM1 for the River Xiangxi. Besides the model uncertainties, projections indicated that the entire discharge distribution shifted toward more extreme events compared to the baseline period. The future mean and extreme events increased for the two river basins.

\section{Discussions}

The projected mean annual temperature of the two catchments showed a consistent increasing trend and the magnitude increased from the 2020s to the 2080s. Most GCMs revealed near-linear increases in annual precipitation and discharge in the two catchments, with the exception of projected decreases in precipitation for the River Xiangxi (CCSM3.0 and ECHAM5) (Fig. 2). However, the changes in projected seasonal temperatures, precipitation and discharges in the two catchments are not univocal. The projected temperatures of the River Huangfuchuan show a lower increase in autumn for all GCMs in the 2020s, but projections from four GCMs show a decrease in the 2080s. The projected seasonal precipitations vary depending on the GCM, time horizon and 

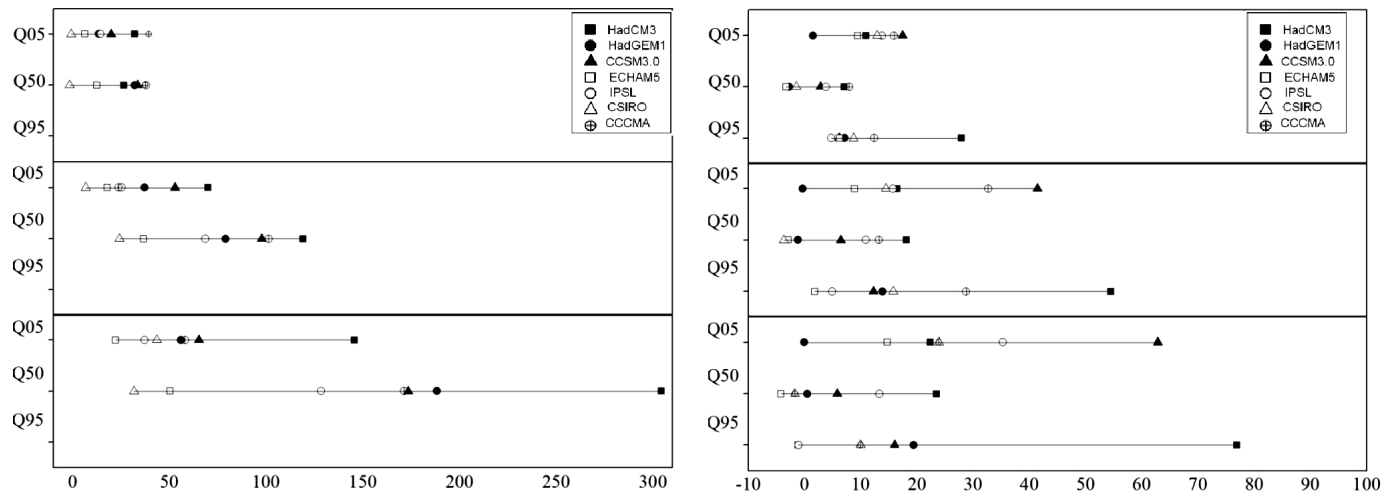

Figure 7. Extreme flow changes for seven GCM projections for the 2020s, 2050s and 2080s time horizons for the rivers Huangfuchuan (left) and Xiangxi (right) (percentage difference from the 1961-1990 baseline) for Q05, Q50 and Q95 (i.e., exceedance in percentage of months over the simulated 30-year period).
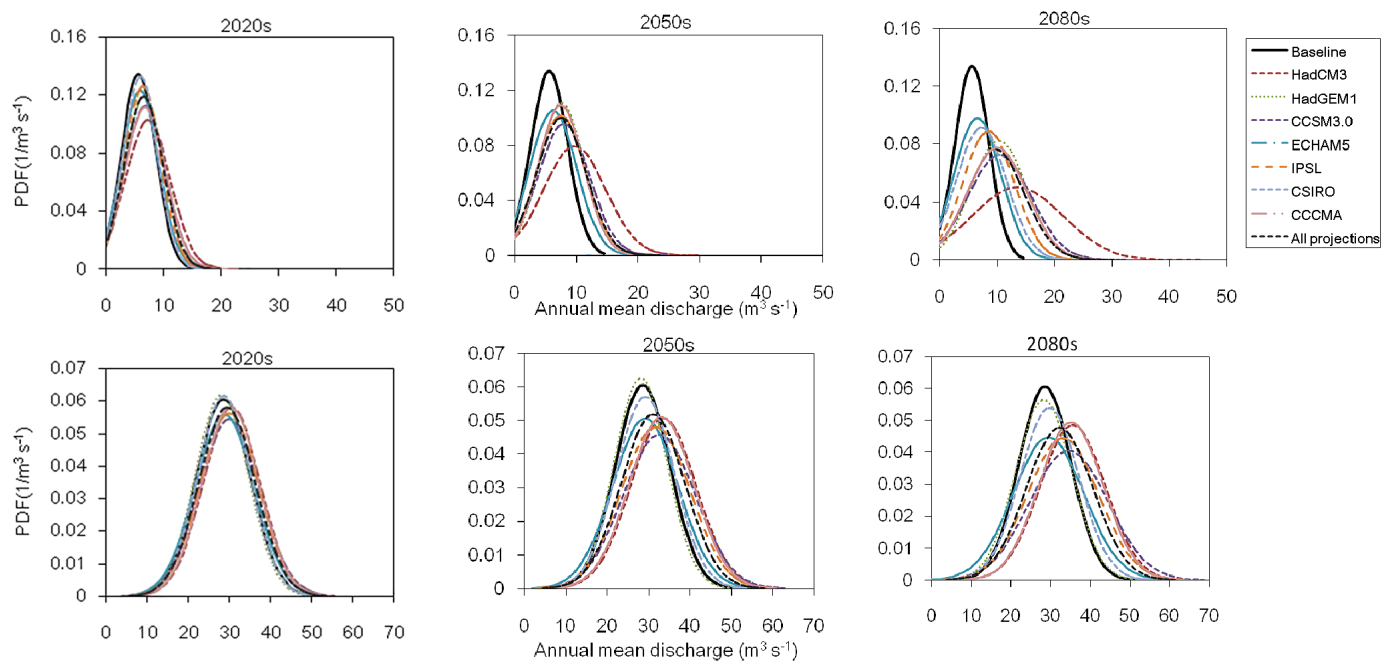

Figure 8. Probability density functions of annual mean discharge for seven GCM projections for the 2020s, 2050s and 2080s time horizons and for the 1961-1990 baseline for the rivers Huangfuchuan (top) and Xiangxi (bottom).

season (Fig. 3). The seasonal discharge is affected by the combination of these variables. The projected seasonal discharges in the River Huangfuchuan appear to increase consistently, with the exception of a projected decrease in summer from ECHAM5 and a decrease in autumn from CSIRO. The changes in seasonal discharge for the River Xiangxi are however much more variable between GCMs. For this reason, to quantify the climate change impacts and assess the uncertainties, multiple GCMs should be used to capture the probability of future change. It has been suggested that the use of two carefully chosen climate projections (dry/hot and wet/cold projections as an example) may be sufficient (Brekke et al., 2004; Singh et al., 2006).

The projected climate changes show obvious differences in the two catchments of different climate regions. The River Huangfuchuan in semi-arid northern China shows more substantial warming and wetting, with larger magnitudes of change in both temperature and precipitation. The River Xiangxi in humid southern China also shows warming, but the increase in precipitation is very slight. These results coincide with increased total annual precipitation, precipitation intensity and extreme precipitation projected for two catchments in eastern China in a future warming scenario (Feng et al., 2011). The increase in precipitation intensity and extreme precipitation is expected to be larger in the middle reaches of the Yellow River basin than in the middle reaches of the Yangtze River basin (Jiang et al., 2011; Xu et al., 2011b). Warmer and wetter scenarios for the River Huangfuchuan are projected to increase river discharge substantially and, if managed properly, this could serve to alleviate current local water shortages. However, on the basis of increasing mean discharge, the projected increase in peak flows may also exacerbate soil erosion in the area of the Loess Plateau. The projected increase in extreme flow in the River Xiangxi may 
be expected to increase the fluxes of nonpoint source pollution and sediment to the river channel. Increasing river discharge has important implications for the management of water resources in both catchments. Increases in mean flow expand available water resources, but the rise in peak flow in both basins could increase flood frequency and flood risk. Therefore, adaptation measures need to consider projected changes in mean and extreme flows, as well as the associated uncertainties.

The results highlight the large uncertainty in climate change impacts due to choice of GCM. During the assessment of the climate change impacts, there are considerable difficulties in choosing appropriate GCMs considering each GCM should be treated equally in the assessment. This study uses all seven of the GCMs to quantify the uncertainties and ranges of impacts on river discharge and provides the basis for water management and further adaptations to climate change. Moreover, choosing certain GCMs in different regions according to pertinent projections is acceptable considering time and calculation limitations. For example, a single variable (temperature) could be chosen for the River Xiangxi for a GCM selection based on having examined the maximum and minimum temperature increases. Nevertheless, in the case of the River Huangfuchuan, the temperatureprecipitation combination was more appropriate based on having examined the cold/dry and the hot/wet extremes.

\section{Conclusions}

There are obvious differences in the climate changes and in the impacts of those climate changes on river discharge in the two catchments. Compared to the catchment in the southern subtropical humid area, the catchment in the northern semi-arid area had more apparent warming and wetting, with a greater increase in river discharge. However, the seasonal changes in temperature, precipitation, and river discharge were more complicated than the annual changes, and the uncertainties were greater among the different models. Moreover, the changes in extreme flows (Q05 and Q95) were different than that for the median flows (Q50). For example, in the River Huangfuchuan, the median river discharge increased greatly, but the changes in extreme flow were less than that for median discharge, so the uncertainty was relatively small. In contrast, in the River Xiangxi, the changes in extreme flows were much larger, leading to larger uncertainties. Thus, changes in extreme flows are far more critical for water managers.

This study revealed the differences between annual and seasonal river discharges in different climate regions and showed the differences between changes in extreme flows and in median river discharge. These findings have important implications for the basin-scale management of water resources in these catchments and for adaptation measures. It is insufficient to examine the impacts of climate change to evaluate adaptations based on a single global model. The uncertainties between projections from multiple GCMs must be taken into consideration.

Acknowledgements. This work was made possible by grants from the National Basic Research Program of China project: Impacts of Climate Change on Terrestrial Water Cycle and Water Resources Safety in Eastern Monsoon Region of Our Country and Adaptation Object (973, Ref. 2010CB428401), and from the Natural Science Foundation of China project: Multi-model Comparison of Hydrological Responses and Uncertainty under the Impact of Climate Change in Different Climate Regions (NSFC, Ref. 40971022). The discussion and helpful insights provided by Daniel Kingston and Tinghai Ou during this study are appreciated.

Edited by: A. Opere

\section{References}

Arnell, N. W.: Effects of IPCC SRES* emissions scenarios on river runoff: a global perspective, Hydrol. Earth Syst. Sci., 7, 619-641, doi:10.5194/hess-7-619-2003, 2003.

Arnold, J. G., Moriasi, D. N., Gassman, P. W., Abbaspour, K. C., White, M. J., Srinivasan, R., Santhi, C., Harmel, R. D., Van Griensven, A., Van Liew, M. W., Kannan, N., and Jha, M. K.: SWAT: model use, calibration and validation, Trans. ASABE, 55, 1491-1508, 2012.

Bates, B. C., Kundzewicz, Z. W., Wu, S., and Palutikof, J. P. (Eds.): Climate Change and Water, Technical Paper of the Intergovernmental Panel on Climate Change, IPCC Secretariat, Geneva, 3-4, 2008.

Brekke, L. D., Miller, N. L., Bashford, K. E., Quinn, N. W. T., and Dracup, J. A.: Climate change impacts uncertainty for water resources in the San Joaquin River Basin, California, J. Am. Water Resour. Assess., 40, 149-164, 2004.

Christensen, J. H., Hewitson, B., Busuioc, A., Chen, A., Gao, X., Held, I., Jones, R., Kolli, R. K., Kwon, W.-T., Laprise, R., Magaña Rueda, V., Mearns, L., Menéndez, C. G., Räisänen, J., Rinke, A., Sarr, A., and Whetton, P.: Regional climate projections, in: Climate Change 2007: The Physical Science Basis, Contribution of Working Group I to the Fourth Assessment Report of the Intergovernmental Panel on Climate Change, edited by: Solomon, S., Qin, D., Manning, M., Chen, Z., Marquis, M., Averyt, K. B., Tignor, M., and Miller, H. L., Cambridge University Press, Cambridge, UK and New York, NY, USA, 853-857, 2007.

Christensen, J. H., Krishna Kumar, K., Aldrian, E., An, S.-I., Cavalcanti, I. F. A., de Castro, M., Dong, W., Goswami, P., Hall, A., Kanyanga, J. K., Kitoh, A., Kossin, J., Lau, N.-C., Renwick, J., Stephenson, D. B., Xie, S.-P., and Zhou, T.: Climate phenomena and their relevance for future regional climate change, in: Climate Change 2013: The Physical Science Basis. Contribution of Working Group I to the Fifth Assessment Report of the Intergovernmental Panel on Climate Change, edited by: Stocker, T. F., Qin, D., Plattner, G.- K., Tignor, M., Allen, S. K., Boschung, J., Nauels, A., Xia, Y., Bex, V., and Midgley, P. M., Cambridge University Press, Cambridge, UK and New York, NY, USA, 12691271, 2013. 
Compiling Committee for "Second National Assessment Report for Climate Change": Second National Assessment Report for Climate Change [M], Science Press, Beijing, p. 46, 2011.

Coulthard, T. J., Lewin, J., and Macklin, M. G.: Modelling differential catchment response to environmental change, Geomorphology, 69, 222-241, 2005.

Feng, L., Zhou, T. J., Wu, B., Li, T., and Luo, J. J.: Projection of future precipitation change over China with a high-resolution global atmospheric model, Adv. Atmos. Sci., 28, 464-476, 2011.

Gao, Q., Jiang, Y., and Li, L.: Analysis on climate change of Huangfuchuan watershed in Middle Yellow River, J. Arid Land Resour. Environ., 19, 116-121, 2005.

Gassman, P. W., Reyes, M. R., Green, C. H., and Arnold, J. G.: The soil and water assessment tool: historical development, applications and future research directions, T. ASABE, 50, 1211-1250, 2007.

Jiang, M., Deng, H., Tang, T., and Cai, Q. H.: On spatial pattern of species richness in plant communities along Riparian Zone in Xiangxi River watershed, Acta Ecol. Sin., 22, 629-635, 2002.

Jiang, Z., Song, J., Li, L., Chen, W., Wang, Z., and Wang, J.: Extreme climate events in China: IPCC-AR4 model evaluation and projection, Clim. Change, 110, 385-401, 2011.

Jiménez Cisneros, B. E., Oki, T.,Arnell, N. W., Benito, G., Cogley, J. G., Döll, P., Jiang, T., and Mwakalila, S. S.: Freshwater resources, Climate Change 2014: Impacts, Adaptation, and Vulnerability. Part A: Global and Sectoral Aspects, Contribution of Working Group II to the Fifth Assessment Report of the Intergovernmental Panel on Climate Change, edited by: Field, C. B., Barros, V. R., Dokken, D. J., Mach, K. J., Mastrandrea, M. D., Bilir, T. E., Chatterjee, M., Ebi, K. L., Estrada, Y. O., Genova, R. C., Girma, B., Kissel, E. S., Levy, A. N., MacCracken, S., Mastrandrea, P. R., and White, L. L., Cambridge University Press, Cambridge, UK and New York, NY, USA, 229-269, 2014.

Jin, T. and Liu, Y.: Geographical conditions for soil erosion and water loss in the Xiangxi valley in the three gorges region and its renovation, Res. Soil Water Cons., 3, 98-110, 1996.

Kay, A. L., Davies, H. N., Bell, V. A., and Jones, R. G.: Comparison of uncertainty sources for climate change impacts: flood frequency in England. Clim. Change 92, 41-63, 2009.

Lahmer, W., Pfützner, B., and Becker, A.: Assessment of land use and climate change impacts on the mesoscale, Phys. Chem. Earth, 26, 565-575, 2001

Liu, C.: The issues in the impact study of climate change on the terrestrial hydrological cycle, Adv. Earth Sci., 19, 115-119, 2004.

Mitchell, T. D. and Jones, P. D.: An improved method of constructing a database of monthly climate observations and associated high-resolution grids, Int. J. Climatol., 25, 693-712, doi:10.1002/joc.1181, 2005.
Moriasi, D. N., Arnold, J. G., Liew, M. W. V., Bingner, R. L., Harmel, R. D., and Veith, T. L.: Model evaluation guidelines for systematic quantification of accuracy in watershed simulations. Trans. Asabe, 50, 885-900, 2007.

Osborn, T. J.: A User Guide for ClimGen: A Flexible Tool for Generating Monthly Climate Data Sets and Scenarios, Climatic Research Unit, University of East Anglia, Norwich, 17 pp., 2009.

Prudhomme, C. and Davies, H.: Assessing uncertainties in climate change impact analyses on the river flow regimes in the UK. Part 2: future climate. Clim. Change, 93, 197-222, 2009.

Rowell, D. P.: A demonstration of the uncertainty in projections of UK climate change resulting from regional model formulation. Clim. Change, 79, 243-257, 2006.

Singh, P., Arora, M., and Goel, N.'K.: Effect of climate change on runoffof a glacierized himalayan basin, Hydrol. Process., 20, 1979-1992, doi:10.1002/hyp.5991, 2006.

Sun, T., Li, B., and Zhang, X.: Climate change characteristics and its ecological effects on Huangfuchuan basin, J. Arid Land Resour. Environ., 26, 1-7, 2012.

Todd, M. C., Taylor, R. G., Osborn, T. J., Kingston, D. G., Arnell, N. W., and Gosling, S. N.: Uncertainty in climate change impacts on basin-scale freshwater resources - preface to the special issue: the QUEST-GSI methodology and synthesis of results, Hydrol. Earth Syst. Sci., 15, 1035-1046, doi:10.5194/hess-15-10352011, 2011.

Wang, S., Yan, Y., Yan, M., and Zhao, X.: Contributions of precipitation and human activities to the runoff change of the Huangfuchuan Drainage Basin: application of comparative method of the slope changing ratio of cumulative quantity, Acta Geogr. Sin., 67, 387-397, 2012.

Wang, X., Cai, H., Zhang, H., Wang, J., and Zhai, J.: Analysis of changing characteristics and tendency of runoff and sediment transport in Huangfuchuan River, Res. Soil Water Conserv., 16, 222-226, 2009.

Wilby, R. L. and Harris, I.: A framework for assessing uncertainties in climate change impacts: Low-flow scenarios for the River Thames, UK, Water Resour. Res., 42, W02419, doi:10.1029/2005WR004065, 2006.

$\mathrm{Xu}, \mathrm{H}$., Taylor, R. G., and Xu, Y.: Quantifying uncertainty in the impacts of climate change on river discharge in sub-catchments of the Yangtze and Yellow River Basins, China, Hydrol. Earth Syst. Sci., 15, 333-344, doi:10.5194/hess-15-333-2011, 2011a.

Xu, C. H., Luo, Y., and Xu, Y.: Projected changes of precipitation extremes in river basins over China, Quat. Int., 244, 149-158, 2011b.

Yang, J., Gao, Q., Li, G., and Jin, Z. P.: A study on the water ecology of some dominant plants in Huangfuchuan Basin, Acta Ecol Sin., 24, 2387-2394, 2004. 